\title{
ON THE INTERSTITIAL GRANULES AND FAT DROP- LETS OF STRIATED MUSCLE
}

\author{
H. HAYS BULLARD
}

From the Anatomical Laboratory, Tulane Universily of Louisiana

\author{
SEVEN FIGURES
}

CONTENTS

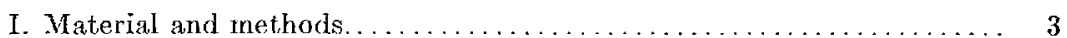

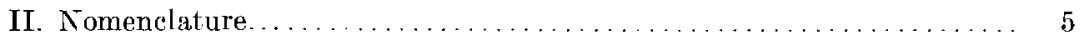

III. Relation of interstitial granules and fat droplets to color and structure

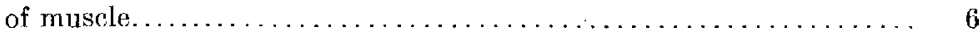

a. Light and dark muscle fibers

b. Relation of light and dark muscle fibcrs to white and red muscle

c. Morphology and position of fat droplets

d. Morphology and position of true interstitial granules

IV. General oceurrence of interstitial granules and fat droplets......... 18

$V$. Chemical nature of interstitial granules and fat droplets . . . . . . 21

a. Chemical nature of true interstitial granules
1. Refractive character
2. Solubility
3. Results with Cresylviolett R R, and Cresylechtviolett
4. Results with the methods of Weigert, Altmann, Benda and Regaud
5. Results with acid fuchsin
6. Results with Sudan III, osmium tetroxide, and gold chloride
7. Summary

b. Chemisal nature of fat droplets

1. Refractive character: Double refraction

2. Solubility

3. Results with Scharlach R and Sudan III

4. Results with osmium tetroxide

5. Results with the Nile blue method

6. Results with the methods of Benda, Fischler, and Klotz for frec fatty acids and soaps

7. Results with the Weigert method and related methods

8. Formalin fixation

9. Summary

VI. Physiological significance of interstitial granules and fat droplots. . . 39

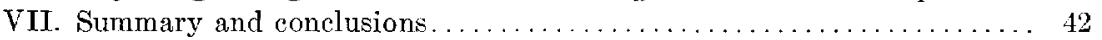

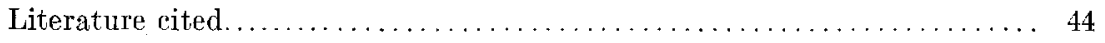


The granules to be found between the myo-fibrils or muscle columns of cross striated muscle, although mentioned by Henle ('41) were first described in detail by Kölliker ('57) who called them 'interstitial granules.' He applied the term to both fat droplets and true interstitial granules, the latter being of a nonfatty nature. This paper presents observations concerning the structure of striated muscle with especial reference to interstitial granules and fat droplets, including also a brief discussion of their general occurrence, chemical nature, and physiological significance. A number of important communications dealing with the interstitial granules have included a somewhat comprehensive review of the literature, namely, Retzius ('90), Arnold ('09), Holmgren ('10), Prenant ('11), and Bell ('11). As several of these papers are of recent date I have thought best to omit a chronological review and shall discuss the literature only in so far as its subject matter has a direct bearing on the topics treated in this paper.

According to Kölliker both fat droplets and true interstitial granules are of wide distribution, occurring in vertebrate muscle and also in insect muscle. A few observers have denied the existence of two general types of interstitial granules, especially in vertebrate muscle, but usually the work of Kölliker has been confirmed in this respect. My observations are in accord with those of Kölliker and I shall likewise designate the types of granules as true interstitial granules and fat granules or fat droplets.

For the present it may be said that true interstitial granules, at least for the most part, are not completely soluble in absolute alcohol and not readily stained by fat stains such as Scharlach $R$, while the fat droplets are easily soluble in absolute alcohol and take the fat stains. This does not necessarily mean that the true interstitial granules contain no fatty substance nor that the fat droplets are composed wholly of fatty substances. Under normal physiological conditions the muscle fibers of both skeletal muscle and cardiac muscle of vertebrates may, and usually do, contain true interstitial granules as well as fat droplets. 


\section{MATERIAL AND METHODS}

For the most part the material was obtained from the common laboratory animals: frog, mouse, rat, rabbit, cat, dog, pigeon, and from the bat. In a few cases the nutritive condition of the animal was altered by special feeding in the laboratory. Human material was used to a considerable extent and insect muscle was also examined.

The methods used in this study have a direct bearing on the chemistry of the granules and fat droplets, and will be discussed in some detail when considering that subject. The methods may be briefly outlined as follows:

1. Examination of fresh material.

a. Preparations made without the addition of fluids.

$b$. Preparations mounted in normal saline solution or 1 to 5 per cent solution of potassium hydroxide.

2. Tests of solubility of interstitial granules and fat droplets with alcohol, xylol, and with ether.

3. Examination of preparations stained by various methods. a. Simple alcoholic solutions of Scharlach R, and Sudan IIr.

b. Herxheimer's Scharlach R.

c. Nile blue sulphate and Nile blue chlorhydrate.

$d$. Cresylviolett and Cresylechtviolett.

$e$. The methods of Weigert, Altman, Benda, and Regaud.

Herxheimer's ('01) stain is prepared by dissolving 2 grams of $\mathrm{Na} \mathrm{OH}$ in 100 ec. of 70 per cent alcohol, Scharlach $\mathrm{R}$ then being added to saturation. The solution is filtered into a tightly closing vessel immediately before being used. Frozen sections or teased preparations of fresh tissue, or material used after two to twelve hours fixation in 20 per cent formalin, are washed in 60 per cent alcohol, transferred to the stain for three to fifteen minutes, washed in 60 to 70 per cent alcohol twenty to thirty seconds, followed by water, and mounted in levulose or glycerine. If alcohol washing is omitted precipitates are formed. Fat droplets are stained red, true interstitial granules and the protoplasm of muscle fibers are not colored. Alum-hematoxylin or Cresylechtviolett may be used as a counter-stain for the nuclei. 
Nile blue: Teased preparations or frozen sections of fresh tissue or material used after a fixation of two to twelve hours in 20 per cent formalin, are stained fifteen minutes to two hours in a saturated aqueous solution of Nile blue chlorhydrate, washed in distilled water five minutes or more, and transferred to tap water. After five minutes in tap water the preparation should assume a reddish hue. If this does not occur a slight amount of alkali may be added to the water. The preparations are mounted in either levulose, potassium acetate, or glycerine. When Nile blue sulphate is used it is necessary to add a somewhat greater amount of alkali, to the tap water. Fat droplets are stained red, purple or blue, true interstitial granules are stained blue.

Cresylviolett: Fresh material, or material after two to twelve hours fixation in formalin, is stained in a dilute aqueous solution of Cresylviolett or Cresylechtviolett for ten to twenty minutes, then washed three to five minutes in distilled water and mounted in levulose syrup. Fat droplets are colorless, or (rarely) a faint red or blue, true interstitial granules are blue.

For the details of the complicated methods of Weigert, Altmann, Benda and Regaud, the reader is referred to Encyklopädie der Mikroskopischen Technik, Berlin, Wien, 1903, and to the discussion of Fauré-Fremiet, Mayer and Schaeffer ('10). Benda's method in particular is unnecessarily complex, requiring about two weeks to prepare a specimen, and its results are not uniform. Satisfactory preparations were obtained by a modified Weigert method which may be briefly stated as follows:

Fix twenty-four hours or more in a 10 to 20 per cent solution of formalin ( 4 to 8 per cent formaldehyde) with the addition of 0.75 per cent sodium chloride, then mordant in 5 per cent aqueous potassium bichromate four to seven days. Imbed in paraffin and section. Stain warm two to six hours in a mixture containing hematoxylin 1 gram and 2 per cent acetic acid $200 \mathrm{cc}$. Decolorize by use of Weigert's differentiating fluid, or by dilute $(0.12$ per cent) potassium permanganate followed by the oxalic acidpotassium sulphite mixture of the Pal-Weigert technique. Dehydrate, clear, and mount in balsam. Or prepare paraffin sections, as above, stain in Altmann's acid fuchsin, decolorize in picric 
acid as used in Altmann's method and then clear and mount in balsam. The true interstitial granules are stained blue by hematoxylin or red if acid fuchsin is used.

\section{NOMEN CLATURE}

In considering the significance of interstitial granules and fat droplets, a clear understanding of the terminology used by various authors is of importance. The true interstitial granules of Kölliker correspond to Altmann's granules or 'bioblasts,' to the 'mitochondria' of Benda, and to the 'plasmasomes' of Arnold. Granules which do not correspond to the interstitial granules but are concerned in the formation of the myo-fibrills, are also included by Altmann, Benda and Arnold, as bioblasts, mitochondria and plasmasomes. A part of the plasmasomes of Arnold, those which are not colored by basic dyes, may represent fat droplets. Benda described mitochondria in fully developed smooth muscle, but thought that they do not occur in the sarcoplasm of adult skeletal muscle, while Holmgren and others, using the technique of Benda, have described such granules in skeletal muscle fibers. The 'exoplasmic granules' ( $J$ granules and Q granules) and the 'endoplasmic granules' of Holmgren' correspond to the 'Sarcosomes' of Retzius which in turn correspond to Kölliker's true interstitial granules. It is possible that Retzius and Holmgren may have occasionally confused fat droplets with sarcosomes.

Albrecht ('02) classed the interstitial granules with his 'liposomes,' which could be demonstrated in all tissues by treating fresh preparations with 5 per cent potassium hydroxide. Since some of Albrecht's liposomes in striated muscle stained by acid fuchsin while others blackened with osmic acid, it is clear that he included as liposomes both the true interstitial granules and fat droplets. Albrecht must have been mistaken in thinking that all his liposomes are seen when fresh tissues are cleared in 5 per cent potassium hydroxide. Fat droplets are brought out clearly but the granules which stain with acid fuchsin are not apparent in such preparations although they may be seen when normal saline is used instead of the alkaline solution. 
Bell ('10, '11) adopted Albrecht's term 'liposome.' As designated by him, none of the liposomes stain with acid fuchsin but all of them may be colored with Herxheimer's Scharlach R and all are soluble in alcohol. He describes certain of his liposomes as faintly-refractive and is evidently of the opinion that they correspond to the faintly-refractive interstitial granules of Knoll, Kölliker and other observers.

I find that the faintly-refractive granules described by Knoll ('80, '91) in the heart and skeletal muscles of the pigeon are readily stained by the acid fuchsin method but do not stain by Herxheimer's method. These granules would thus come within the category of liposomes as the term is used by Albrecht, but they form no part of the liposomes of Bell. The faintly-refractive liposomes of the latter author are faintly-refractive fat droplets and do not correspond to the faintly-refractive granules of Knoll. Knoll himself pointed out that his faintly-refractive granules correspond to the true interstitial granules of Kölliker.

The term true interstitial granules will be used in this paper to correspond to the true interstitial granules of Kölliker which as previously mentioned include a part of the bodies described by Altmann, Benda, and Arnold respectively, as bioblasts, mitochondria and plasmasomes.

The term ' $\mathrm{fat}$ ' is here used to include lipoids and cholesterin compounds as well as the fatty acids and their glycerin esters.

III. RELATION OF INTERSTITIAL GRANULES AND FAT DROPLETS TO COLOR AND STRUCTURE OF MUSCLE

\section{a. Light and dark muscle fibers}

Krause ('64) found that the fibers of the red muscles of the rabbit contain more interstitial granules than are present in the fibers of white or pale museles. Grützner ('84) described two types of fibers in human muscles, cloudy or dark and pale or white. He found that all human muscles contain both types of fibers and believed that dark fibers give macroscopically the red appearance to muscles while light fibers correspond to white or pale muscles. 
Knoll ('89) concluded that the dark appearance of muscle fibers is due to the presence of interstitial granules, the dark fibers, he states, have many granules while light fibers are free from granules or contain only a small number. Knoll ('91) described the dark fibers as rich in interfibrillar substance or sarcoplasm ("protoplasmareich') and as containing many interstitial granules, while the light fibers were poor in intcrfibrillar substance (protoplasmaarm') and contained few granules. As a rule, red muscles contained more dark fibcrs while whitc muscles consisted of light fibers to a large extent. The dark fibers wcre usually of a smaller diameter than light fibers. Knoll also held that in general the active muscles contain a larger proportion of dark muscle fibers with a corresponding increase in the number and size of the interstitial granules. Schaeffer ('93) confirmed the work of Grützner and Knoll. He also found that dark fibers showing fixed contraction nodes simulate light fibers. Bell ('11) found that, in general, dark fibers contained coarse, strongly-refractive 'liposomes,' while light fibers contained small faintly-refractive liposomes. He stained the liposomes (fat droplets) with Herxheimer's solution of Scharlach $R$ and in this way demonstrated the types of fibers.

The reader is referred to the papers of Knoll, Schaeffer, and Bell for an account of the general occurrence and distribution of light and dark fibers in different animals. The work of these authors has shown that differences in opacity, corrresponding to light, dark, and intermediate fibers, occur in the striated muscles of many animals, including practically all those most commonly employed in the laboratory.

In my studies the light and dark fibers were easily observed in transverse sections of fresh tissue cut on the freezing microtome. The difference in opacity is most marked when the specimen is mounted in normal saline and examined with low magnification, the reflected light being cut off by a paper shield or by some other means. The types of fibers were also demonstrated by staining frozen sections with Herxheimer's Scharlach R, with Nile blue, or with Cresylviolett. In the pectoral muscles of the pigeon 
where the true interstitial granules are large and numerous, the types of fibers were distinguished by the Weigert and Altmann methods as well as by the other methods just mentioned.

The light, dark and intermediate types of muscle fibers are clearly marked in unstained frozen sections of fresh material from normal cats, dogs and rats. If such sections be placed in absolute alcohol for a few minutes and subsequently examined under the microscope the dark and intermediate fibers assume the appearance of light fibers. The fat droplets and also the alcohol-soluble portion of the true interstitial granules have been removed by the alcohol, and the removal of these droplets and granules causes the dark fibers to lose their opacity. In the dog, cat and rat the true intersitial granules are small and the opasity of the dark fibers is largely due to fat droplets. In the pectoral muscles of the pigeon and the bat, not only fat droplets but also true interstitial granules are an important factor in causing the dark appearance of fibers. Sections of formalin fixed material from the pectoral muscles of the pigeon after treatment with absolute alcohol ten to twelve hours still show the dark fibers much more opaque than the light, while in similar preparations from the dog, cat or rat, dark fibers have lost their opacity and have the appearance of light fibers. The fat droplets have been removed by the alcohol but the large true interstitial granules of the pectoral muscles of the pigeon remain and causc the opaque appearance of the dark fibers to be retained. The staining reactions and solubility of fat droplets and true interstitial granules will be dealt with later, but I may here mention that formalin coagulates the true interstitial granules in such a manner as to partially protect them from the action of fat solvents while fat droplets are readily soluble both before and after formalin fixation.

Figure 1 represents the types of fibers in the pectoralis major of an exceptionally well nourished white rat. The preparation was stained by Herxheimer's method. Figure 2 shows a similar specimen from a very emaciated rat. The dark fibers so apparent in the well nourished animal have largely disappeared in the poorly nourished animal. The granules shown in the figures are 

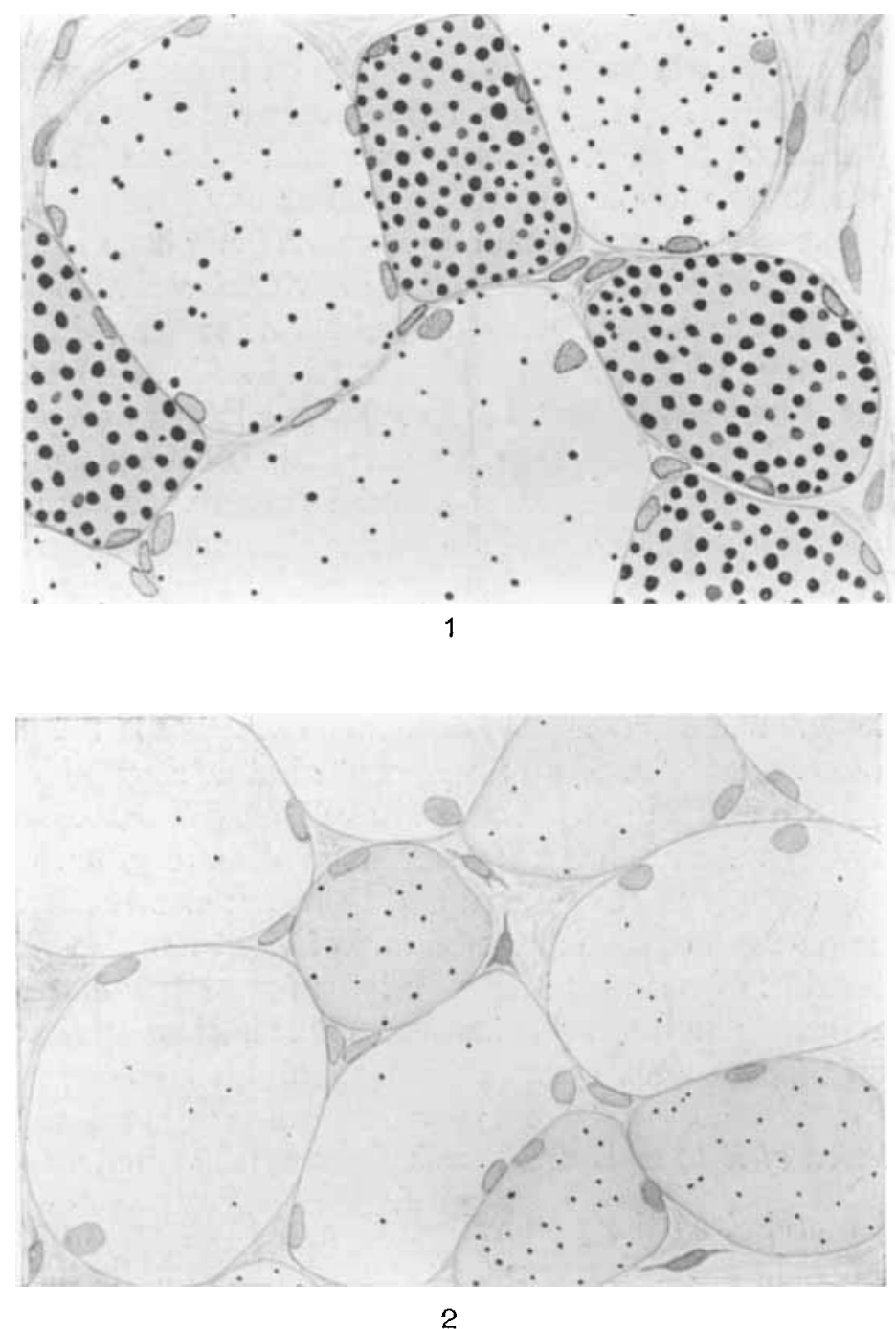

Fig. 1 Transverse section of muscle fibers from the pectoralis major of a rat which had been fed on fat meat. Fat droplets (black) are stained red by Hcrxheimer's Scharlach R. The larger fibers are 'light fibers', the 'dark fibers' are smaller. $\times 600$.

Fig. 2 Transverse section of musele fibers from the pectoralis major of an emaciated rat. Fat droplets (black) are stained red by Herxhcimer's Scharlach R. Both 'light and 'dark' fibers are shown. $\times 600$. 
fat droplets. Bell ('11) first clearly demonstrated that the fat content of muscle is largely dependent upon the nutritive condition of the animal. This subject will be referred to later.

The relative number of light, dark and intermediate fibers is known to be exceedingly variable. For any given muscle of a given species the percentage of each type is fairly constant under normal nutritive conditions, although individual variation occurs. Dark fibers have more interfibrillar substance or sarcoplasm and are commonly of lesser diameter than light fibers. However, the dark fibers in eye muscles (human) are as large or even larger than the light fibers. In the pectoralis major of the pigeon light fibers are exceptionally large with nuclei placed in the substance of the fiber, while dark fibors are small and the nuclei are peripherally situated. Mammalian skeletal muscle, in so far as I have observed, has peripherally situated nuclei in both types of fibcrs. The pectoral muscles of the bat are peculiar in that the fibers are all small and correspond to dark fibers as found in the pigeon. The fat content of the dark fibers of the bat as shown by Herxheimer's Scharlach $R$ varies somewhat in the different fibers and this may be considered as an indication of the two types.

The two types of fibers, dark and light, are clearly marked in the human fetus of seven months and of eight months. I have also found the two types in the ox fetus from 45 to $65 \mathrm{~cm}$. and at full term. In so far as I know dark fibers in the fetus have not been previously described.

\section{b. Relation of light and dark muscle fibers to white and red muscle}

Red muscles, as the pectoralis major of the pigeon and bat, commonly show a high percentage of dark fibers, while the white muscles of the rabbit and certain other animals may be made up largely or wholly of light fibers. By many text books and by even a recent author, Ewald ('10), the terms red and white muscle fibers are used synonymously with dark and light fibers. Such a terminology is probably founded upon a misconception and should be discontinued. The white muscles of the frog during the winter season show under the microscope a large percentage of very dark fibers and frequently red muscles, as cardiac muscle 
in certain individuals, show only light fibers. It is clear that dark fibers do not necessarily give a red color to muscle nor does the prescnce of light fibers in red muscle make it less red in appearance.

According to Krause ('11) red and white muscles in the rabbit differ only in number and arrangement of blood vessels and in amount of connective tissue. I am unable to say to what extent the red color of muscle is due to the presence of blood. Lelièvre and Retterer ('09) studied the structural differences between the red and white muscles of the rabbit. They concluded, among other things, that the membrane of Krause ( $Z$, Strie d'Amici) is absent from white muscle (adductor magnus). I have examined the fibers of the adductor magnus of the rabbit and find the membrane of Krause present and clearly visible in both fresh and fixed preparations.

\section{c. Morphology and position of fat droplets}

Krause ('73) observed a regular arrangement of the interstitial granules in transverse rows situated in segment $J$ on either side of Krause's membrane, $Z$. The observations of Krause have been confirmed by Retzius ('90), Arnold ('00), Holmgren ('07,'10), and many others, and it has also been observed that the position of the granules as described by Krause applies to that of both the true interstitial granules and fat droplets. Retzius, Holmgren and others have described large interstitial granules as occurring in the anisotropic segment $Q$, (Brücke's disc).

The fat droplets of muscle fibers are in general spherical. Their form may be modified by the pressure of the muscle columns. Droplets that have a diameter exceeding one micron frequently show a certain amount of elongation in the direction of the longitudinal axis of the fiber. Exceptionally, the longitudinal diameter of elongated droplets is nearly twice the transverse diameter. Upon contraction of the fiber, droplets become more spherical or even flattened in the transverse direction. Occasionally, and especially in human muscle, the fat has a granular form, the evenly rounded contour of droplets being absent. Possibly this is due to post mortem changes. I am not here referring to the pigment 
granules of irregular form so frequently present in human muscle, especially in cardiac muscle.

Fat droplets occur in varying sizes. Apparently the smallest droplets are beyond the limit of microscopic vision. Bell ('11), staining muscle fibers by Herxheimer's method, shows 'liposomes' (his fig.4, plate 16) which measure less than $0.5 \mathrm{~mm}$. after a magnification of 1300 . This means that they have a diameter of less than $0.5 \mu$. According to Heidenhain ('00), $0.2 \mu$ is the extreme lower limit of microscopical vision (n. a. l. 4), and if perchance any structure of smaller size were visible it would still appear to have a diameter of 0.2 micron. Herxheimer's Scharlach $R$, as well as Nile blue frequently forms precipitates in the tissues but precipitate granules lack the refractive character of fat droplets and when of appreciable size the two are easily distinguishable. Precipitate in a finely granular form may be confused with minute fat droplets, and for this reason I have preferred to regard as probably a precipitate, all granules having an approximate diameter of $0.5 \mu$ or less. The diameter of the fat droplets, which di" ers with the nutritive condition and with the species of the animal, seldom, if ever, exceeds $3 \mu$ in normal mammalian muscle. Fresh preparations stained in Herxheimer's Scharlach R often show droplets as large as 5 to $6 \mu$, but the examination of fresh material to which no foreign fluids have had access has convinced me that such large globules arise by the confluence of smaller droplets.

The fat droplets seldom show a regular arrangement within muscle fibers in preparations made from fresh material without fixation. To demonstrate the position of fat droplets, portions of muscle were stretched upon card board or small pieces of glass and while still warm placed in 20 per cent formalin in a 0.75 per cent solution of sodium chloride. After fixation of two to twentyfour hours, sections were cut on the freezing microtome and stained by Herxheimer's method or by the Nile blue method.

Figure 3 shows the droplets in a portion of a longitudinal scetion of a dark muscle fiber from the pectoralis major of an adult cat. The droplets are in transverse rows in segment $J$ on either side of the membrane of Krause, $Z$. An arrangement in longitudinal rows is also apparent. Figure 4 represents a portion of a light 
fiber from the same specimen. The droplets are fewer in number and somewhat smaller than in the dark fibers. The arrangement is similar in the two types. Droplets may be smaller than those shown in the figures and placed nearer to the membrane $Z$, thus making it difficult to see two distinct rows. Droplets in dark fibers which show a large quantity of fat, may all be of small size, not exceeding $1 \mu$ and arranged as in figure 3. Dark fibers may show longitudinal rows of small droplets placed at frequent intervals between less frequent rows of larger, elongated droplets.

In transverse sections the droplets are situated between the muscle columns or Cohnheim's areas. The larger droplets are at nodal points in the sarcoplasmic net work. No droplets are found between the individual myofibrils within the muscle columns. In muscle fibers of a type which have large true interstitial granules (granules of segment $Q$, pectoral muscles of the pigeon and bat and in cardiac muscle), the fat droplets when small are placed in segment $J$, while larger droplets extend into segment $Q$. In this type of muscle the droplets in segment $J$ may be placed on either side of the membrane of Krause, $Z$, but frequently droplets are in a single row occupying the position of the membrane. Fat droplets are also of almost constant occurrence in the sarcoplasm beneath the sarcolemma and surrounding the muscle fiber nuclei of skeletal muscle, and they are equally constant in the central perinuclear sarcoplasmic accumulations of eardiac muscle.

\section{d. Morphology and position of true interstitial granules}

Figure 5 represents the true granules in one of the dark muscle fibers of the pectoralis major of the pigeon, longitudinal section, Weigert method. The granules are rod shaped, being approximately $1 \mu$ in diameter and $2 \mu$ in length. In position they correspond to segment $Q$ and represent Holmgren's $Q$ granules. Figure 6 represents a portion of a similar fiber, from the same muscle, stained with Nile blue sulphate after formalin fixation. By this method true interstitial granules are stained blue while fat droplets are colored red. The fat droplets, for the most part, are situated in segment $J$ at the poles of the true interstitial gran- 
ules. Occasionally the substance of the $Q$ granules appears to partially surround a fat droplet. In formalin-bichromate material with the Weigert and Altmann methods, vacuoles left by the extraction of fat droplets during the paraffin process, are sometimes seen within the substance of the granule but usually the vacuoles are in segment $J$ at the poles of the granules as shown in figure 5. The vacuoles thus correspond in position to the polar fat granules which Holmgren describes as of occasional occurrence.

Transverse sections show the true interstitial granules between the muscle columns. When demonstrated by the formalin-bichromate Weigert or Altmann methods, they appear rounded; or flattened in transverse section. In frozen sections stained with Cresylviolett or Nile blue sulphate, the granules are seen as stellate bodies which may occupy almost the entire space between the muscle columns (fig. 7). In describing this appearance in unstained preparations, Kölliker ('88) speaks of granules provided with wing shaped processes.

When frozen sections of formalin fixed material are treated with absolute alcohol and subsequently stained, Cresylviolett stains the true interstitial granules (pectoral muscles of the pigeon) rather faintly but the processes which give the stellate or irregular

Fig. 3 Portion of a longitudinal section of a dark muscle fiber from the normal pectoralis major of an adult eat. Fat droplets (black) are stained red by Herxheimer's Scharlach $R$. Membrane of Krause is situated at $Z$; $Q$, position of anisotropic dise, $\times 1500$.

Fig. 4 Portion of a longitudinal section of a light muscle fiber from the normal pectoralis major of an adult cat; stained as in figure $3 ; Z$, position of Krause's membrane; $Q$, position of anisotropic dise. $\times 1500$.

Fig. 5 Portion of a longitudinal section of a dark muscle fiber from the normal pectoralis major of a pigeon. 'True interstitial granules, $g$, (black) are stained blue by a modified Weigert process. Fat droplets appear as vacuoles, $a$. The letter $m$ indicates muscle columns; $z$, Krause's membrane. $\times 1500$.

Fig. 6 Portion of a dark musele fiber from the normal pectoralis major of a pigeon, stained by Nile blue. Fat droplets, $a$, are stained red (black); true interstitial granules, $g$, are stained blue (gray); $m$, muscle columns; $z$, Krauses' membrane, $\times 1500$.

Fig. 7 Transverse section of a dark fiber and a portion of a light fiber from the normal pectoralis major of a white rat, stained with Cresylviolett. Fat droplets, $a$, are colorless or a faint red, true interstitial granules, $g$, are stained blue (black). The letter $m$ indicates muscle columns. $\times 1500$. 

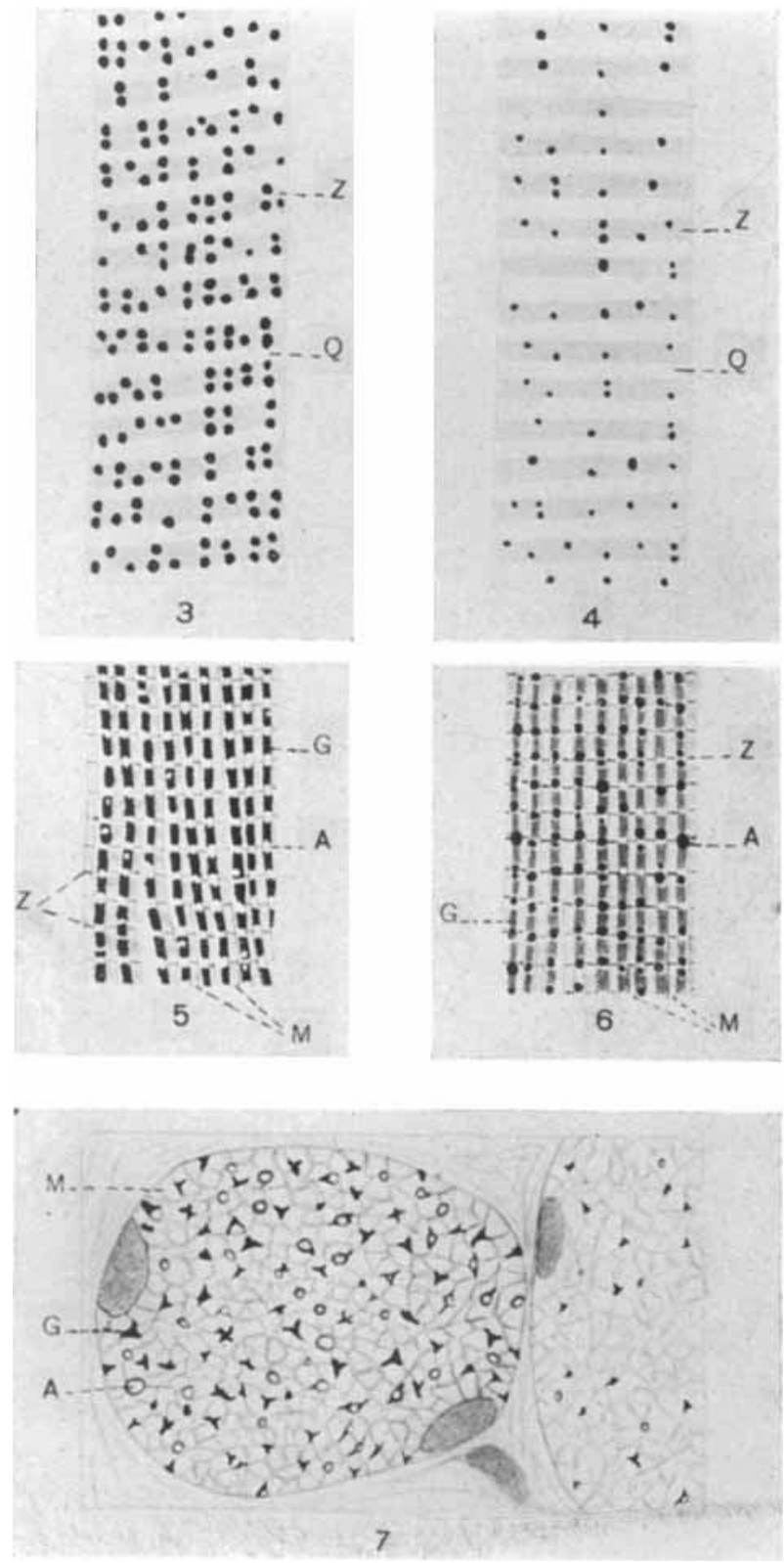
appearance in transverse section are evidently not present. Nile blue still stains the granules with intensity but no stellate forms are visible. In this process, the fat droplets have been removed by the alcohol and also much of the substance which stains with Cresylviolett has apparently been extracted from the fiber or rendered incolorable. In formalin-bichromate material stained as either Weigert or Altmann preparations, paraffin sections, the granules seldom present the stellate form. The wing shaped processes of Kölliker may be dissolved during the process of paraffin embedding. Holmgren, however, has sometimes demonstrated the wing shaped processes by Benda's mitochondrial method.

The true granules were described above as having a rod shaped form in the breast muscle of the pigeon. This is not to be taken as invariably true. I have also observed in the pigeon muscle, dumb-bell and diplosomic forms in longitudinally cut fibers. At other times the shape is irregular and the granule is not wholly confined to the anisotropic segment. The longitudinal rows of granules in the light fibers of the pectoralis major of the pigeon are placed at greater intervals than in dark fibers though the granules are somewhat smaller in the former.

The true granules of the pectoral muscles of the bat are similar in number, size, and position to those of the pigeon. However, in the skeletal muscle of most mammals (dog, cat, rabbit) the granules are of smaller size and fewer in number. In logitudinal sections they may be dumb-bell shaped, rodules, or slender thread structures, either confined to segment $Q$ or extending through the entire distance between adjacent membranes of Krause, $Z$. They may occur as spherical bodies having a diameter of $1 \mu$ or less and situated in segment $J$ on either side of Krause's membrane. The appearance is then similar to that shown. for fat droplets in figure 3. The occurrence of true granules in segment $J$ is described by Holmgren ('10) as typical for mammalian skeletal muscle. The stellate or irregular forms in transverse sections shown by staining with Cresylviolett were of constant occurrence in all the animals used in this investigation. They may be demonstrated in both light and dark fibers, even when granules appear to be absent by the Weigert and Altmann methods. 
In cardiac muscle (pigeon, dog, rat) the true interstitial granules are present in very striking numbers. They are usually confined to the segment $Q$ and correspond to Holmgren's $Q$ granules. Regaud ('09) described and figured the granules in the cardiac muscle of the $\operatorname{dog}$ as plate-like structures, confined to segment $Q$ and extending radially between the muscle columns from the periphery of the fiber toward the central sarcoplasmic column. I have examined the cardiac muscle of several dogs and find the true interstitial granules as described by Regaud.

In the wing muscle fibers of insects the granules are very similar in form and position to either the granules of the pectoral muscle the pigeon and the bat or to those of cardiac muscle in vertebrates. The wing muscle fibers of the Belostoma Americana show rounded granules in transverse section similar to those of the pigeon. The fibers of dragon flies have granules of a platelike form similar to those of the cardiac muscle of the dog. I have not examined fibers from the leg muscles of insects.

Retzius ('09) believed that the interstitial granules are united and held in position by a fibrous network, which he demonstrated with gold chloride. A comparison of gold chloride preparations with others made by the various methods already mentioned, leads me to believe that the appearance of a net work uniting the interstitial granules is to be interpreted as a precipitate of gold.

The position assumed by the granules appears to be determined solely by their size and the pressure of the muscle columns. Perhaps also the position of both the true interstitial granules and fat droplets may be taken as affording evidence in support of the now commonly accepted view that the membranes of Krause are present in the sarcoplasm between the muscle columns. The dumb-bell and diplosomic granules may be formed by a thickening of the muscle columns at Hensen's line. After fixation, and due to the process required for embedding, the substance of the column shrinks leaving its impress upon the granules. The platelike forms occur in types of muscle that present a radial arrangement of the muscle columns. The substance of the granule occupies the space between the columns and thus, in transverse sections, appears in the form of a plate. 
In general it may be said that the shape of the true interstitial granules indicates that in fresh, unfixed muscle they are composed of a plastic, yielding substance which easily takes the form imposed by surrounding structures of a more resistant nature. Probably the term granule is a misnomer, but it is here used because it has become firmly fixed in the literature.

Kölliker ('88), Holmgren ('07, '10), Thulin ('09) and Knoche ('09) believed that the true interstitial granules possess a limiting membrane. In Weigert, Altmann, Cresylviolett and Nile blue preparations, I have observed nothing which can be taken as indicating the existence of such a membrane. The membranelike appearance in fresh unstained preparations is, in all probability, an optical effect due to differences in refractive index.

\section{GENERAL OCCURRENCE OF INTERSTITIAL GRANULES AND FAT DROPLETS}

\section{General occurrence of true interstitial granules}

Kölliker ('89) described the true interstitial granules as of constant occurrence, sometimes in enormous numbers, in the striated muscle fibers of all classes of vertebrates and insects. Knoll ('91) observed the true interstitial granules in a large number of animals including amphibians, reptiles, birds and mammals. Retzius ('09) described his sarcosomes (true interstitial granules) in insects and manmals. Altmann ('94) demonstrated the granules in insects and in the frog. Holmgren ('07-'10) described Kölliker's granules as occurring in insects and in vertebrates, rabbit, guinea pig, rat and white mouse.

The large true interstitial granules are included in nearly every description of insect muscle. Similar granules in vertebrate muscle, although described by the investigators just mentioned and by many others, have frequently been overlooked. This applies not only to text books but likewise to recent original articles.

The white muscles of the rabbit show, by the Weigert or Altmann method, only a few granules or none at all and the red muscles may show but a limited number. In the dark fibers of the dog and the gray rat, granules are larger and somewhat more 
numerous than in the rabbit, especially in the muscles of the tongue and in the diaphragm. In the powerful and active pectoralis major of the pigeon and of the bat, the true interstitial granules as demonstrated by the Weigert method are relatively large and occur in great numbers in each fiber (fig. 5). In so far as I have observed, the granules which stain blue with Cresylviolett, (fig. 7), may be demonstrated in considerable numbers in every striated muscle fiber of all vertebrates. As already mentioned, granules to be demonstrated by this method do not always correspond with those shown by the Weigert and Altmann methods.

In cardiac muscle, as pointed out by Kölliker, Knoll and Holmgren, the granules are especially abundant. I have examined the heart muscle of the dog, the rat and the pigeon. The number and size of the granules is very striking. I have not been able to demonstrate the true interstitial granules in human cardiac or skeletal muscle, due doubtless to the fact that fresh material was not obtainable.

\section{General occurrence of fat droplets}

Kölliker ('88, '89) describes fat droplets as of general occurrence in muscle fibers of insects and vertebrates. However, he was evidently somewhat in doubt as to their being true fat droplets. He speaks of the droplets as fat like granules or as the long known dark (fat?) granules. Walbaum ('99) examined the muscles of 119 human bodies. He found fat droplets in some of the fibers of about two-thirds of the cases examined. Droplets were most numerous in the eye muscles and of very infrequent occurrence in the diaphragm. Ten per cent formalin was used as a fixative. He examined teased preparations in water and in normal saline and observed that many of the fatty droplets are left unstained by Sudan IIr. Retzius ('91) believed that fat droplets are not normally present in muscle fibers. Among others Stadkewitch ('94), Ricker and Ellenbeck ('99) and Kemp and Hall ('07), may be mentioned as failing to find fat droplets in the normal muscle fibers of adult vartebrates. As is well known, the muscle fibers of the winter frog are crowded with fat droplets while such drop- 
lets are usually supposed to be absent in summer frogs caught in the field.

Fat droplets have often been overlooked in skeletal muscle due to the fact that they are so frequently lost in the fixatives employed (formalin) and may often be left unstained by osmic acid and Sudan III. Bell ('11) who employed Herxheimer's Scharlach R on fresh tissue has demonstrated that 'liposomes' occur under normal conditions in all vertebrate muscle. He states that the number and size of the liposomes vary in different species and individuals and also with nutritive condition. He examined no human muscle.

The dog, cat (figs. 2 and 3) and rat (figs. 1 and 2) may be mentioned as examples of animals commonly having a large quantity of fat in their skeletal muscle fibers while the fibers of the ox and the rabbit have considerably less. I think that an extensive investigation might show that fibers of herbivorous animals do not store fat to such a great extent as is the case in carnivora.

Human skeletal muscle. I have examined some of the muscles, usually diaphragm, pectoral and eye muscles from about twentyfive autopsies and conclude that fat droplets occur constantly and abundantly in normal human muscle. Fat in the diaphragm was present in large amount in about half the cases examined. In two or three cases the droplets in the fibers of this muscle were few in number or possibly absent but I think that this may be attributed to pathological conditions, poor nutrition or to post mortem change. I have never failed to find fat in human eye muscle, usually in large amount.

Cardiac muscle. I have examined sections from the right ventricle of the hearts of about twenty-five dogs and cats, a dozen rats and several mice. Fat in varying amounts was found within the muscle fibers of all these animals. In two dogs only a few small droplets were to be seen, but usually in this animal fat was present in moderate amount. An exceptionally large amount of fat was present in the cardiac muscle fibers of a well nourished rat and of a pregnant cat.

Human cardiac muscle. Of fifteen hearts, fat droplets were present in ten. Two or three of the remaining five were examined 
after most decided post mortem changes had taken place. Fat droplets in the human cardiac fibers are commonly regarded as occurring only under pathological conditions. I believe that a thorough investigation of the subject, with the aid of the best technique would demonstrate that fat droplets of small size are of normal occurrence in human cardiac muscle fibers.

Fetal muscle. Kainath (04) examined the skeletal muscles of the ox fetus. He found fine fat droplets in the fibers from the 3.5 to the $12.5 \mathrm{~cm}$. stage but none were present in the fetus of $20 \mathrm{~cm}$. and $40 \mathrm{~cm}$. Bell ('09) found fat in the muscle fibers of the ox fetus from the 7 to the $28 \mathrm{~cm}$. stage, but observed none in the fibers of seven fetuses of later stages.

The muscle fibers of the early fetus were not examined in this study but I have found a large amount of fat in the fibers of the ox fetus from the $35 \mathrm{~cm}$. stage to full term. The dark fibers contain many fat droplets while light fibers have but a small number. I have also examined the skeletal muscles of a seven months and eight months human fetus. The dark fibers were crowded with fat droplets.

\section{CHEMICAL NATURE OF INTERSTITIAL GRANULES AND FAT DROPLETS}

A qualitative chemical analysis, in vitro, of the true interstitial granules and fat droplets of muscle fibers is beset with obvious difficulties and such an investigation has never been attempted. One can, however, draw certain conclusions respecting the chemistry of these bodies by a consideration of the nature of the various methods used in demonstrating them in tissue sections.

\section{a. Chemical nature of true interstitial granules}

Kölliker ('57) states that the true interstitial granules, being very pale, especially in mammalian muscle, have been overlooked by previous observers. He finds the granules insoluble in alcohol and ether. Kölliker ('88) concludes that, chemically, the granules are identical with no known substance. They contain no glycogen for they do not give the iodine reaction. Retzius ('90) 
considers the true interstitial granules to be of a non-fatty nature. He terms them 'sarcosomes' in order to distinguish them from pathological fat droplets. Knoll ('80, '81, '91) believes the true interstitial granules of Kölliker to have a fatty marginal layer and a central portion possibly of lecithin. Arnold ('07) thinks that the glycogen of striated muscle is bound to the sarcosomes. He observed that sarcosomes which contain glycogen stain by Best's carmine method ('06) while those that are free from glycogen remain colorless. Regaud and Favre ('09) demonstrated granules in the tongue muscles of the rabbit by Regaud's formalinbichromate iron-hematoxylin method. They believed these granules to correspond to Kölliker's granules. Chemically they were thought to be an albumino-lipoid. Bell('11) finds that the large $Q$ granules of insects contain no fatty substance and are widely different chemically from the interstitial granules of vertebrate muscle. He thinks that the microsomes of Altmann may be artefacts, and is evidently of the opinion that other observers have mistaken fat droplets in vertebrate muscle for the true interstitial granules.

1. Refractive character. Fibers from the pectoralis major of the pigeon or the wing muscles of an insect may be teased and placed, without the addition of fluid, upon a slide, the cover glass being applied with slight pressure. Such preparations show the fat droplets as highly-refractive globules but the true interstitial granules seem to have approximately the same refractive index as the substance of the muscle columns and are not clearly visible. However they may be seen as faintly-refractive bodies after normal saline has been drawn under the cover-glass.

2. Solubility. As has been observed by Kölliker and others the true interstitial granules are disintegrated and partially dissolved by water. In order to test the effect of fat solvents upon the granules I have examined sections prepared by the paraffin. process after fixation. in 97 per cent alcohol. In sections from the heart or pectoral muscles of the pigeon, the granules in alcohol fixed material are seen as broken fragments. A comparison of these sections with others made after formalin-bichromate fixation shows that a large part of the substance of the granules has disappeared from the alcohol fixed material. This suggests the idea 
that the partial disappearance of the granules from alcohol fixed material may be due to the solution of a fatty substance which can be rendered insoluble by the action of potassium bichromate. It was found, however, that the granules of material fixed in 20 per cent formalin show no more shrinking after the paraffin process than do those of formalin fixed material which has been mordanted in potassium bichromate before the alcohol and xylol preceding embedding. Thin paraffin sections were also washed in several changes of hot ether four to six hours and subsequently examined under the microscope after staining with acid fuchsin or hematoxylin. The fat extraction by this method is considcred more complete than by the Soxhlet's apparatus as ordinarily employed. Ether does not dissolve the true interstitial granules from paraffin sections of formalin fixed material taken from the pectoral muscles of the pigeon. The partial disappearance of the granules, from alcohol fixed material, takes place in the alcohol and xylol, and the subsequent treatment with ether appears to have little effect. If we suppose that the shrinkage or disappearance of the granules in alcohol or xylol is due to the extraction of a fatty substance, it is also necessary to suppose that the fatty substance is in part rendered insoluble in alcohol, xylol and ether by the coagulative action of the formalin on the non-fatty substance of the granules. As will be seen below, however, staining with Cresylviolett indicates that the true interstitial granules are soluble in alcohol to a very considerable extent even in formalin fixed material

3. Results with Cresylviolell $R$ R, Cresylechtviolett, and Nile blue sulphate. Krause ('11) recommends Cresylviolett R B in dilute aqueous solution for demonstrating the interstitial granules in fresh tissue. I have used Cresylechtviolett and Cresylviolett $\mathrm{R} R$ which are apparently similar to the dye employed by Krause. The fat droplets are not stained to any considerable extent by Cresylviolett. Occasionally they show an exceedingly faint red color or a more intense peripheral blue staining but usually they are left colorless.

As mentioned above, the true interstitial granules are partially dissolved by water. Since this is the case, one should 
not expect to obtain a true picture of the granules by the use of an aqueous staining solution on unfixed material. The arrangement of the granules is often very irregular in Cresylviolett preparations of unfixed material especially if the section is cxposed to the action of water previous to staining or left too long in the stain, or if the material is taken from animals following rigor mortis. Under such circumstances granules are absent from portions of the fiber and are aggregated in masses within other portions of the fiber or beneath the sarcolemma. The blue stained substance, however, is not easily, if at all, soluble in water. Aqueous solutions of Cresylviolett may also be applied to frozensections of material fixed fresh for two to twenty-four hours in 20 per cent formalin in a 0.75 per cent sodium chloride solution. Such preparations show a comparatively uniform arrangement of the blue staining granules corresponding to that of the true interstitial granules of Kölliker.

It has already been mentioned that the wing shaped processes of Kölliker, which give the granules a stellate appearance, are not stained by Cresylviolett when the section has been previously treated with alcohol. In formalin fixed material the large granules of the pectoral muscles of the pigeon can be stained intensely with Nile blue or faintly with Cresylviolett even after the action of alcohol. The true intersititial granules in the muscle fibers of the dog, cat, rat and rabbit stain with Cresylviolett and for the most part appear to be soluble in alcohol both in fresh material and in formalin fixed material for they cannot be stained when sections have been previously treated with absolute alcohol. When this material has been kept in 20 per cent formalin for several weeks, the wing-shaped processes and soluble granules seem to have disappeared and can no longer be demonstrated by Cresylviolett or Nile blue sulphate. Even after prolonged exposure to formalin the true interstitial granules in the pectoral muscles of the pigeon are still readily stained by Nile blue sulphate and faintly colored by Cresylviolett.

If it be supposed that the alcohol-soluble substance of the true interstitial granules is a form of fat, the fact that it stains with basic dyes may indicate that it is a lipoid or fatty acid. 
4. Results with the methods of Weigert, Altmann, Benda and Regaud. To demonstrate the true interstitial granules, Altmann ('94) employed his bichromate-osmic acid-fuchsin method. Holmgren ('10) made use of Bend's mitochondrial method and Regaud ('09) used his formalin-bichromate iron-hematoxylin method. I find that the granules may be demonstrated in a satisfactory manner by any of the above methods as well as by the Weigert method which involves formalin-bichromate fixation followed by hematoxylin staining. Similar results by these methods is to be expected for the methods are chemically similar although the stains employed, acid fuchsin, Crystallviolett, hematoxylin, and iron-hematoxylin, are of a varied character.

Smith, Mair and Thorp ('08) have explained the chemistry of the Weigert hematoxylin process. They found that the method depends upon the oxidizing action of potassium bichromate upon unsaturated fats. The oxide of ehromium forms with the fat molecules a compound which is insoluble in fat solvents and capable of forming a lake with hematoxylin. It is only during the process of oxidation that the fat-chrome compound forms the hematoxylin lake. After complete oxidation the staining no longer takes place. These observers found the method applicable not only to unsaturated fats, as oleic acid and triolein, but also to lipoids in which unsaturated groupings occur such as cholesterin and cerebrosides. The work of Smith, Mair, and Thorp was confirmed and extended by Fauré-Fremiet, Mayer, and Schaeffer ('10). They found that not only the unsaturated but also certain of the saturated fatty acids, including palmitic, are rendered insoluble in alcohol and xylol by oxidizing reagents and also by the action of salts of the heavy metals. (Benda explained the action of the salts of copper on fatty acids as depending upon the formation of insoluble copper soaps.) These insolubilized fats were stained with more or less intensity by both acid and basic anilin dyes and in certain cases (after copper or chromic compounds, salts of iron and of zinc) a hematoxylin lake was formed. The phosphatid lipoids were not rendered insoluble in xylol by the action of salts of the heavy metals, but were insoluble after chromic and certain other 
oxidizing compounds. Lipoids rendered insoluble by chromic compounds stained with considerable intensity by Orange $G$ but could be stained with the anilin dyes only when the potassium bichromate had been kept warm during the process of oxidation. The hematoxylin lake in the case of the lipoids, did not follow excepting after a mordant such as iron alum. It was also observed that both albumino-lipoids (lecithalbumin) and mixtures of fatty acid and albuminoids were precipitated by formalin in such a way as to render the fatty substances practically insoluble in ordinary fat solvents. For example, oleic acid in a precipitated albuminous mixture was stained by various methods, even after the action of alcohol and alcohol-ether for several days at a temperature of $35^{\circ} \mathrm{C}$. The methods of Altmann, Benda and Weigert, although variously modified are, according to these observers, based on the same chemical principles and give almost identical results when applied to the mitochondria (Altmann's granules or the true interstitial granules of this paper). After an extended inquiry into the chemistry of the mitochondria, they conclude that the granules contain a fatty body which is neither a neutral fat nor a soap but is probably an unsaturated fatty acid, absorbed by an albuminous granule or present in an albuminolipoid compound.

If we assume with the authors just quoted and with Regaud and Favre ('09) that the true interstitial granules are an albuminolipoid or a fatty-acid albuminous mixture, the action of formalin in partially protecting them against fat solvents is explained in that the albuminous component is coagulated by the formalin and the fatty component is thus rendered less easily extractable. The same assumption also permits us to explain the action upon the granules of the methods of Altmann, Benda, Weigert and Regaud. It would, of course, be a mistake to consider these methods as specific for albumino-lipoids. They are of wide application and do not afford distinctive evidence as to the chemical nature of the substances stained.

5. Results with acid fuchsin. Knoche ('09) obtained a microchemical xanthoproteic reaction with the true interstitial granules of Kölliker and belived that the proteid thus shown was an 
albuminous substance. He states that the granules have a capsule which stains with acid fuchsin but he does not give the details of his technique. As has been previously mentioned, the entire granule is readily stained in formalin-bichromate material with Altmann's acid fuchsin. Employing material from the pectoral muscles of the pigeon and bat and from the wing muscles of insects, I have also found that Altmann's acid fuchsin stains the granules after simple formalin saline fixation (paraffin process) the potassium bichromate being unnecessary. The fragmonted granules in alcohol-fixed material are not stained by Altmann's acid fuchsin.

Smith and Mair ('11) find that lecithin and sphingosine stain readily with acid fuchsin both before and after the action of potassium bichromate. They think the presence of either of these substances would explain the staining of Altmann's acid fuchsin granules. Pure lecithin, according to these observers, does not stain by the Weigert process, but they add that it stains readily if it has the slightest admixture of cholesterin. Fauré-Fremiet, Mayer and Schaeffer ('10) state that lecithin and other lipoids fail to stain by the Weigert process, but may be stained by hematoxylin if preceded by iron alum. Since the true interstitial granules stain. readily by the Weigert process, the iron alum not being necessary, we may conclude that if the staining of these granules depends largely on lecithin, as suggested by the acid fuchsin method, the lecithin is not in a pure state.

Fatty acids, according to Smith and Mair (11), do not stain with acid fuchsin either before or after the action of potassium bichromate. Fauré-Fremiet, Mayer and Schaeffer ('10), on the other hand, find that fatty acids are faintly stained by this dye, both before and after bichromating, presumably with greater intensity in the latter case, for they think that the presence of fatty acid would account for the staining of Altmann's granules. I have stained tissue paper smears of oleic acid (Kahlbaum) after treatment for a variable length of time (one to six days) in saturated potassium bichromate. The smears wère stained with acid fuchsin either Altmann's mixture or in alcoholic solution, heating according to the method of Altmann. The droplets were stained 
a somewhat pale red. The color in the case of oleic acid appears to be too faint to fully account for the intense red of the true interstitial granules, and thus it is doubtful that these granules contain a pure oleic acid.

6. Results with Sudan III, osmium tetroxide, gold chloride. Sudan III does not color the true interstitial granules unless we take into account an extremely faint yellow to be obtained after the action of potassium bichromate. The granules are slightly darkened, but not blackened, by 2 per cent osmic acid followed by pyroligneous acid or by alcohol for reducing the osmium. Retzius ('90), Knoll ('91), and others have stained the true interstitial granules with gold chloride but the gold precipitate is not considered differential for the presence or absence of fat.

7. Summary. The observations presented above are of too general a character to permit of definite conclusions as to the chemical nature of the true interstitial granules of Kölliker. It is certain that the granules contain a non-fatty element, probably of a proteid nature. It may be stated that the substance upon which depends their staining by basic dyes, as well as by the more complex methods of Altmann, Weigert and Regaud, is a substance soluble in fat solvents. In part this soluble substance may be protected from fat solvents by the action of formalin as well as by chrom-osmic mixtures. The solubility and staining reactions of the granules indicates that they may be an albumino-fatty compound or mixture, possibly an albumino-lipoid. There is no reason to suppose that the granules in muscle fibers are fundamentally different chemically from granules to be demonstrated by similar methods in other tissues of the body. It is reasonable to suppose that the true interstitial granules of muscle fibers are subject to some variation chemically in different species and under varying nutritive conditions.

\section{b. Chemical nature of fat droplets}

The fat droplets of muscle fibers are mentioned by many observers but few have attempted to determine the exact chemical nature of the fat. Usually, it seems, the droplets have been looked 
upon as neutral fat. As already mentioned, Knoll ('80, '81, '90) thought the true interstitial granules to be composed, in part at least, of lecithin, but he too considered the fat droplets to be neutral fat. Bell ('10) holds that neutral fat droplets in muscle fibers are readily stained by simple alcoholic solutions of Scharlach $\mathrm{R}$, but many 'liposomes', which are not so highly refractive as neutral fat droplets and consist wholly or in part of lipoids, can be stained only by alkaline Scharlach $R$ (Herxheimer's method). Bell ('11) thinks the liposoms consist mainly of olein together with some low-melting fat other than olein. He states that many faintly-refractive liposomes which do not stain readily with simple alcoholic solutions of Scharlach $R$ or with osmic acid, are stained somewhat faintly by Herxheimer's method and are composed in part of a substance other than fat, possibly an albumino-lipoid. Liposomes which stain faintly by Herxheimer's method and contain a non-fatty element are believed by Bell to be of most common occurrence in the muscle fibers of poorly nourished individuals.

1. Refractive character: Double refraction. The fatty droplets of muscle fibers may be seen in fresh tissue to which no foreign substance has had access. Preparations are made by rapidly teasing the fibers on a slightly warmed slide and applying a cover glass with slight pressure. The droplets present the highly refractive appearance characterisitic of fat droplets and must be regarded as pre-existing bodies, that is to say they are notproduced by histological reagents. Fat droplets are well brought out in fresh preparations mounted in normal saline. They vary somewhat in refractive index in different individuals but usually the variation in a single preparation is not pronounced. The true interstitial granules may also be observed in such preparations. These granules likewise vary somewhat in refractive index but are usually less refractive than the fat droplets. Judging merely from refractive index certain granules may be classed as either faintly refractive fat droplets or highly-refractive true interstitial granules. Preparations mounted in 2 to 5 per cent potassium hydroxide show the fat droplets very clearly for an hour or more but the true granules disappear almost immediately. 
Bell ('11) states that the fat droplets of muscle fibers are all isotropic. I have examined only a few specimens with the micropolariscope. The droplets were always singly and not doubly refractive. This shows that the droplets are not a fat which is fluid crystalline in form, such as the cholesterine compounds.

2. Solubility. The fat droplets of muscle fibers are readily soluble in cold absolute alcohol and in ether. Ninety-five per cent alcohol usually dissolves the droplets from frozen section or teased preparations in a few minutes. Tissue fixed in seventy per cent alcohol frequently shows a gradual diminution of the quantity of fat. It is well recognized that tests of solubility are of little value in determining the chemical character of fats in the tissues, especially as such fats, at least in most cases, are not in a pure state but exist as mixtures. Neutral fat has usually been considered insoluble in 70 per cent alcohol. However the fat droplets of muscle fibers, having a diameter of but 1 to $3 \mu$, must be regraded as in an extremely fine state of division, thus favoring prompt solution and, moreover, the quantity of solvent is very many times that of the fat dissolved. The fact that fat droplets in muscle fibers are sometimes dissolved by 70 per cent alcohol does not prove that they are not neutral fat.

3. Results with Scharlach $R$ and Sudan III. Bell ('10) states that I had shown clearly the great superiority of alkaline alcoholic solutions of Scharlach $\mathrm{R}$ and mentions that my results had not yet been published. My observations concerning the staining of fat droplets in muscle fibers with alkaline alcoholic solutions of Scharlach R and Sudan III and with simple alcoholic solutions of the same dyes, were made in the Laboratory of Anatomy of the University of Missouri three years ago and are here given in a corrected form. At that time I observed the position of fat droplets in muscle fibers, a subject already discussed in this paper.

Schlarlach $R$ and Sudan III are usually employed as saturated solutions in 70 to 80 per cent alcohol. Such solutions frequently fail to stain the fat droplets of muscle fibers. The best results are obtained by heating the alcohol at the time of preparation of the stains or by permitting a certain amount of evaporation during the staining process. Even after an application of twenty- 
four hours, these stains may color only a small part of the total number of fat droplets which can be seen in fresh preparations or demonstrated with Nile blue. Herxheimer ('04) does not state specifically that bis alkaline-alcoholic solution of Scharlach $R$ will color any fat droplets which cannot be stained with simple alcoholic solutions but he quotes Erdheim ('03) as having made such a claim. In so far as I have observed, alkaline-alcoholic solutions of Scharlach R and Sudan mi stain all the fat droplets of muscle fibers. Herxheimer's stain usually gives a deep red color to droplets faintly stained or left colorless by simple alcoholic solutions. As already stated, true interstitial granules are not stained by Sudan III and Scharlach R. Frozen sections or teased preparations of muscle fibers, as well as of other tissues, which, when stained by the ordinary stock solutions of Sudan III and Scharlach $R$ in 70 per cent alcohol may appear fat free, are sometimes shown to be crowded with fat droplets whon examined in the unstained condition or when stained with Herxheimer's stain, or with Nile blue followed by immersion. in an alkaline medium. In some specimens of muscle the simple alcoholic solutions stain all the fat droplets which can be seen in the fresh tissue.

The fact that fat droplets in muscle fibers are frequently left unstained by the less concentrated solutions of Sudan III and Scharlach $R$ does not seem to offer sufficient proof that such droplets are not neutral fat. Fat in adipose tissue of mammals which presumably is neutral fat, is occasionally colored so faintly by these stains that were it in finely divided droplets it would be almost colorless. I do not share the belief advanced by Bell that we must suppose the droplets to contain an admixture of albumin or other non-fatty substance. The droplets in the muscle fibers of emaciated individuals, in so far as I have observed, stain with as great intensity by Herxheimer's method as do those of well nourished individuals. The intensity with which droplets are stained both with Herxheimer's stain and with simple alcohollic solutions of Scharlach $R$ depends as much upon the conditions under which the dye is used as upon the nature of the fat. The fact that droplets stain faintly cannot in itself be taken as sufficient proof that they contain a non-fatty element. 
4. Osmium tetroxide. It is well known that osmic acid is reduced only by the unsaturated fats, the reduction depending upon the oxidation of the fat. Therefore it has been considered that fat droplets that are blackened by osmic acid consist, wholly or in part, of unsaturated fats. However, unsaturated fats present in small amounts as mixtures with saturated fats may fail to blacken with osmic. The fat droplets in muscle fibers of many animals do not reduce osmic acid. While in certain individuals the fat droplets blaken with osmic acid, in other individuals of the same species the reduction does not occur. This shows that the unsaturated fat in the droplets is variable in amount.

5. Results with the Nile blue method. Smith ('07) explained the staining of fats with the basic anilin dyes as depending upon the formation of color-soaps by the action of fatty acids and color bases. Neutral fat, as such, can not be stained by basic anilin dyes, but after hydrolysis the free fatty acid combines with the color base. This observer also found that neutral fat in the tissues is in a very unstable condition, being hydrolyzed by dilute acids and even by the carbon dioxide of the air. Thus neutral fat droplets in stained sections, after having been hydrolyzed into fatty acid and glycerine by exposure to the air were observed to take the color of the basic stain. Smith found that Nile blue sulphate initially gives a red color to both neutral fat and fatty acid. Neutral fat retains the red staining quality but subsequently fatty acids form color-soaps with the Nile blue base, the deep blue of the soap obscuring the comparatively faint red color of the fatty acid. Aschoff ('09) found that the phosphatid lipoids and cerebroside are also colored blue by Nile blue sulphate. MeCrae and Klotz ('10), who used Nile blue on sections of fatty liver, state that they experienced some difficulty in interpreting their results. According to Klotz ('09) "The blue coloration obtained in staining sections with Nile blue is not to be depended upon as indicating in every instance the presence of fatty acids, as the shade of the color is influenced by external circumstances." He, however, does not specifically state by what circumstances the color is influenced.

Nile blue has been used as a means of investigating the chemical nature of fat droplets in tissue sections, but in so far as I know 
the method has not been applied to muscle fibers. I have followed directions given by Smith and Mair ('11) for the use of Nile blue sulphate but the results have not been very satisfactory. Apparently the fat droplets are decolorized by the 2 per cent acetic acid used as a differentiating fluid. The method which I have used with best success is given here under the heading "Material and methods." In brief it consists in setting free the color base by the addition of a small amount of alkali to the medium in which the section is mounted, or by washing in slightly alkaline water after differentiating in distilled water. Precipitates are formed if sections are not carefully washed before being placed in the alkaline solution. With a little care in making the preparations with Nile blue chlorhydrate, and apparently with the sulphate also, it is possible to stain all the fat droplets to be found in muscle fibers. That is to say, Nile blue will stain droplets that are not stained by simple alcoholic solutions of Sudan IIr and Scharlach $\mathbf{R}$ or by osmic acid. With Nile blue, as with other stains, fresh tissue should be used if all the droplets are to be stained, for they frequently disappear in fixed tissue.

As has already been said, Nile blue sulphate stains not only the fat droplets but, in formalin fixed material at least, it also stains the true interstitial granules. This is best shown by staining a section from the pectoral muscle of a pigeon or bat. The true interstitial granules are especially abundant and stain a bright blue, the shade depending upon the length of time in the stain and upon the reaction of the mounting medium. The fat droplets which may also be present in large numbers, usually stain a somewhat faint red but sometimes in various shades of purple or blue. In formalin fixed specimens of material containing large true interstitial granules, it is not difficult to distinguish the latter from. fat droplets since the granules do not have the globular form of the droplets and for the most part present color differences.

The color assumed by the fat droplets when stained with Nile blue is of some importance as it may help in identifying the fats chemically. The color of the droplets depends, to a considerable extent upon the time occupied in staining and upon the alkalinity of the solution to which the stained section is exposed, as well as 
upon the length of time left in this second solution. The red staining takes place rapidly. The blue staining is sometimes well marked after fifteen minutes but may not appear for several hours or may not occur at all. The color is also influenced by the reaction of the mounting medium. In any alkaline medium the pale blue droplets tend to become red, while in an acid medium the red droplets tend to become blue. The entire mass of droplets may stain uniformly either red, blue, or in various shades of purple. On the other hand, a droplet colored red may include within its mass one or several clearly marked smaller droplets which stain an intense blue. Again, the periphery of a droplet may show blue staining while the center is red. After preparations have been mounted for a variable number of days, droplets which at first were red may assume an intense blue color. In other preparations the red color is retained for months. I have observed a certain amount of blue staining of the fat droplets in every species of animal from which material was taken, including man. The blue staining compound is found in muscle fibers taken from well nourished animals as well as in fibers from animals poorly nourished.

It is difficult to interpret the color reactions of Nile blue upon the fatty substances of muscle fibers. The blue color of fat droplets may possibly indicate that they are, in part, either fatty acid or a lipoid substance, while the red color indicates the presence of neutral fats. However, the blue color of the fat droplets may, as we have seen, indicate the presence of a neutral fat which is easily hydrolyzed, the fatty acid then forming a color soap. When the blue staining takes place only after sections have been mounted several days, it is, in all probability, dependent upon the gradual hydrolysis of neutral fat. With fresh tissues treated with the dye for a few minutes only, the blue staining, which is sometimes immediately apparent, may be due to similar changes in the neutral fat. It is possible that blue staining of fat droplets in fresh unfixed tissue or in tissue obtained some time after the death of the animal, may be due, in part, to the solution in the fat droplets of the blue staining substance of the true interstitial granules. It was pointed out by Smith ('07) that fat droplets in 
tissues may be hydrolyzed by the action of the formalin fixatives. It follows that in formalin fixed material the blue staining with Nile blue is often an expression of neutral fat which has undergone hydrolysis.

The fat droplets of the muscle fibers of many individuals of a species show no blue staining after a prolonged exposure to the stain. From this we may conclude that the droplets in these individuals contain little or no free fatty acids, phosphatid lipoids, or cerebroside. In no case, in so far as I have observed, does the staining with Nile blue afford convincing proof that any substance other than neutral fat is normally present in the fat droplets of muscle fibers during the life of the animal. Contrary indications may be due to postmortem changes.

6. Results with the methods of Benda, Fischler and Klotz for free fatty acids and soaps. According to Benda, neutral copper acetate forms, with free fatty acids, colored copper soaps which for the most part are insoluble in fat solvents. The methods of Benda, Fischler and Klotz depend upon this reaction. Fischler ('04) found that the fatty acid copper compound forms a lake with hematoxylin. He also stained soaps in the tissues by the same methods, the soluble potassium and sodium soaps being first converted into insoluble calcium soaps by the action of calcium salicylicum. Klotz ('06) suggested further modifications. Bell ('11) used the above methods on preparations from a considerable number of muscles, but in no case was able to get the color reaction for free fatty acids or soaps. He concludes that the liposomes (fat droplets) of muscle fibers do not contain either fatty acids or soaps. I have used these methods only to a limited extent and my results are in agreement with those of Bell. However a positive result with the methods of Fischler and Klotz should not be taken as certain proof of the existence of free fatty acid during life. The fixative employed in both these methods contains formalin and in the method of Klotz, acetic acid is added. It is thus possible that the staining occasionally depends upon the previous hydrolysis of neutral fat.

7. Results with the Weigert method and related methods. We have already discussed these methods and seen that they give 
positive results with the true interstitial granules. The fat droplets of muscle fibers are not easily rendered insoluble by the action of chromic compounds. For the most part the droplets are dissolved by the alcohol or xylol used in the paraffin process even when the tissues have been treated with 10 per cent potassium bichromate for several days at $37^{\circ} \mathrm{C}$. It follows then that the fat droplets in muscle fibers are not shown by the Weigert or iron-hematoxylin methods as ordinarily employed. When chrom-osmic fixatives are used, as in the methods of Altmann and Benda, the droplets are sometimes blackened and rendered insoluble, but usually they are still soluble. When, as rarely happens, fat droplets are rendered insoluble by the bichromateosmic mixtures, and at the same time not blackened by osmic, they may be stained by Benda's iron-alum Krystallviolett and probably also by hematoxylin or iron-hematoxylin. Since the investigations of Smith and Mair ('08, '10, '11), Aschoff ('09), and of Fauré-Fremiet, Mayer and Schaeffer ('10) have shown that the phosphatid lipoids, combinations of cholesterin and fatty acids, as well as cerebroside, are rendered insoluble by the action of potassium bichromate, we may conclude that the fat droplets of muscle fibers do not, to any very considerable extent, consist of these fats. Saturated neutral fats are not rendered insoluble by the action of potassium bichromate and triolein is acted upon only very slowly. The fat droplets of muscle fibers not being readily acted upon by potassium bichromate, react as if they were composed wholly or largely of neutral fat.

8. Formalin fixation. Bell ('10) pointed out the fact that fat droplets in muscle fibers and other tissues are frequently not preserved by formalin fixation. Droplets of ordinary neutral fat he states are not affected in their staining by formalin fixation, but many faintly-refractive fat droplets, consisting wholly or in part of lipoids, cannot be stained after formalin fixation. The faintly-refractive droplets are either removed or rendered invisible by fixation. He finds that the action of the formalin fixative in one tissue may be unappreciable for weeks and in another nearly all the liposomes may be removed in a few minutes. He states that the varying effect of the fixative is probably due to the vary- 
ing chemical composition of the liposomes. Bell also found that usually the fat droplets in the muscle fibers of adult and well nourished animals are less affected by formalin than are the droplets of young and poorly nourished animals. However, many exceptions to this rule were mentioned. Bell ('11) confirms his former observations and states further that the faintly-refractive liposomes, which are removed by formalin fixation, consist in part of a substance other than fat, possibly an albumino-lipoid. He believes that the disappearance of the liposomes is probably due to autolysis.

I have repeatedly observed the gradual disappearance of fat droplets from tissue fixed in formalin. However, I am not certain that neutral fat is not affected by formalin fixation. Smith ('11) in fact has found that ordinary formalin solutions hydrolyze the fat droplets of frozen sections which are kept in the fixative. I have frequently but not invariably found that the blue staining of fat droplets with Nile blue is more marked in formalin fixed material. Free fatty acids are soluble in Herxheimer's staining solution and hence cannot be demonstrated by Herxheimer's method. The fat droplets of formalin fixed material frequently disappear, not being visible either as crystals or as droplets staining blue with Nile blue. This indicates that the final change which takes place in the fat is not be to explained on the basis of simple hydrolysis. I believe, however, that the initial change may be hydrolysis of an unstable neutral fat. The fat droplets of the muscle fibers of the ox fetus, for the most part, stain red with Nile blue but after several days the droplets in the stained section assume a blue color. This change of color indicates that the fat is in an unstable condition and can be readily hydrolyzed. The fat droplets of the fetal tissue were not permanently preserved by formalin fixation. The observations of Bell and Smith, as well as my own, are based on the use of ordinary commercial formalin. This solution contains variable quantities of formic acid and possibly acetic acid. The hydrolysis of the fat may depend upon the presence of these impurities. It is thus possible that the variable action of formalin is to be explained in part by the variable chemical composition of the fixative. 
The action of formalin on the fat droplets is not what we should expect if the droplets were an albumino-lipoid as suggested by Bell. In fresh unfixed muscle fibers the droplets readily coalesce to form larger globules. In formalin fixed material the coalescence is not so apparent, for the substance immediately surrounding each droplet has been coagulated. However by the examination of carefully teased muscle fibers it is easy to convince oneself that the droplets themselves are not hardened but may still coalesce. If albumin were present to any considerable extent, the droplets would be fixed and no coalescence would take place. Faure-Fremiet and his collaborators have shown that albuminolipoids are coagulated by formalin in such a manner as to render the fatty substance almost insoluble in fat solvents. The fat droplets of formalin fixed muscle fibers are apparently as easily dissolved by alcohol as in fresh tissue.

9. Summary. The fat droplets of muscle fibers are not largely composed of fatty acids or soaps for they do not stain by the methods of Benda, Fischler and Klotz. They are not fatty acids for they do not stain readily with basic anilin dyes. The fat droplets do not contain cholesterin esters to a very considerable extent for they do not present the characteristic anisotropic fluid-crystalline form. The droplets are not phosphatid lipoids or cerebroside for these substances are easily rendered insoluble by potassium bichromate, whereas the fat droplets of muscle fibers are not rendered insoluble. Also phosphatid lipoids and cerebroside stain with basic dyes, giving blue with Nile blue, while the fat droplets of muscle, at least for the most part, stain red with this dye and are colored blue only after a chemical change has occurred in the fat. Fat droplets in muscle fibers are readily stained by alkaline-alcoholic solutions of Scharlach R and Sudan III but are frequently left unstained by simple alcoholic solutions of these dyes. The evidence which tends to show that the fat droplets of muscle fibers are neutral fat (glycerin esters of fatty acids) is largely of a negative character. It is improbable that they are pure neutral fat, yet it may be said that no certain proof has yet been offered that any substance other than neutral fat is present in the fat droplets of muscle fibers during the life of the animal. 
VI. PHYSIOLOGICAL SIGNIFICANCE OF INTERSTITIAL GRANULES AND FAT DROPLETS

\section{Physiological significance of true interstitial granules}

Several investigators have held that true interstitial granules give origin to fat droplets either by a fatty metamorphosis or by serving as a focus about which fat is deposited. Kölliker ('88-89) belived that fat droplets in muscle fibers arise from true interstitial granules by a process of fatty metamorphosis and Schaeffer ('93) advanced similar views. Holmgren ('10) states that the deposition of fat in muscle fibers is apparently influenced by the true interstitial granules but he thinks the granules are actually transformed into fat only under exceptional or pathological conditions. Altmann ('94) held that his bioblasts (true interstitial granules) are not transformed in toto into fat but act as a focus within and around which fat is accumulated. Arnold has advocated similar views. Bell ('11) does not believe that granules which stain with acid fuchsin (Altmann's granules) give origin to fat and he is of the opinion that true interstitial granules do not occur in vertebrate muscle. His conception of the deposition of fat in muscle fibers is nevertheless essentially in accord with the theory advanced by Altmann. Bell holds, namely, that the fat of muscle fibers is deposited as 'liposomes' around a pre-existing non-fatty body, possibly an albumino-lipoid. As we have seen, Altmann's granules are probably an albumino-lipoid formation and conversely albumino-lipoids may be expected to stain with Altmann's acid fuchsin.

The reader is referred to the literature for a presentation of the arguments offered by various authors in support of the idea that true interstitial granules give origin to fat droplets or serve as foci about which fat is deposited. It may be said that, at present, the truth of such a conception is not sufficiently demonstrated to warrant us in believing that there is a genetic relationship between true interstitial granules and fat droplets.

According to Holmgren ('07, '10) the colorable substance (method of Benda) of the interstitial granules is necessary to the proper functioning of the contractile elements. During the 
latent period, substance from the granules was thought to pass into the musele columns there to be used in the stage of active contraction. The examination of insect and vertebrate muscle fibers, by the various methods employed in this study, has afforded little in support of Holmgren's views concerning the physiological significance of the granules.

Knoll ('80) and Knoll and Hauer ('92) found that the true interstitial granules are not removed in inanition. Feeding experiments with a dozen white rats lead me to conclude that the alcohol-soluble portion of the true interstitial granules which stains with Cresylviolett is increased in amount when rats are heavily fed and decreased when the animals are kept on low rations. This may indicate that the alcohol-soluble substance is of metabolic importance and such an assumption would seem the reasonable one.

Before dismissing the subject of the physiological significance of true interstitial granules, it should be mentioned that Arnold ('09) believes that glycogen is bound to the sarcosomes (true interstitial granules), and Kingsbury ('12) thinks that mitochondria, in general, act as a reducing agent and in certain cases may be concerned in exercising the function of cell respiration.

\section{Physiological significance of fat droplets}

The presence of fat droplets in striated muscle fibers has been regarded by Van Gehuchten ('89) and others, as of pathological significance. Probably this is still the prevailing opinion with respect to cardiac muscle. Schaeffer ('93) believed that fat droplets in the skeletal muscle fibers of vertebrates may occur under normal conditions but are usually pathological. Walbaum ('99) found that fat droplets were of very frequent occurrence in normal human muscle fibers but thought the quantity of fat bore no direct relation to the nutritive condition of the individual. Kölliker ('88) regarded the fat droplets of insect muscle as reserve food material. Knoll and Hauer ('92) found that fat droplets in the muscle fibers of pigeons are removed by starvation but the true interstitial granules are not removed. Krause ('11) states that the fat droplets in muscle fibers are not independent of the 
nutritive condition of the animal. Bell ('11) found that the liposomes (fat droplets) of the striated muscle fibers of rats were entirely removed when the animal was starved until it had lost 25 per cent or more in body weight. During starvation, the liposomes gradually became faintly refractive and decreased in size, number and in staining intensity with Herxheimer's Scharlach $\mathrm{R}$ and with osmic acid. When the starved animal was again given food the liposomes gradually reappeared, increasing in size, number, refractive power, and staining intensity as the animal gained weight. In normal rats which were fed on fat meat for several days, the liposomes were greatly increased in number, size, and staining intensity. When summer frogs were fed heavily on olive oil or fat meat, there was a striking increase in size, number and staining intensity of the liposomes. No changes were produced in the liposomes by the feeding of grape sugar, starch, palmitic acid, sodium oleate, or lean meat. Since the liposomes stained faintly when they first appeared, Bell supposed that they then contained a relatively small percentage of fat together with some substance other than fat, possibly an albumino-lipoid. $\mathrm{He}$ regarded the liposomes as foci wherefat is deposited and concluded that they consist of reserve food substances mainly, at least, in the form of fats.

In this connection I have examined the muscle fibers of a dozen white rats on various nutritive planes. Figure 1 represents fibers from the pectoralis major of an adult rat which had been heavily fed on fat meat for seven days. The fat droplets were stained with Herxheimer's Scharlach R. Figure 2 shows muscle fibers from the pectoralis major of a rat which had been kept for ten days on short rations of a fat free diet consisting mainly of cellulose. Fat cells were almost completely absent from the subcutaneous tissue and mesentery of this animal. Fat droplets are practically absent from the light fibers as shown in the figure, while dark fibers have a smaller quantity of fat than is normally present even in light fibers. In the diaphragm of this animal, the quantity of fat, although greatly reduced from the normal, was somewhat greater than that found in the pectoralis major.

The amount of fat in the cardiac muscle fibers of emaciated rats was less than in fibers of well nourished individuals. Animals 
fed on fat meat showed an increased amount of fat in the cardiac fibers but the increase was not so great as in skeletal muscle. The muscle fibers of the pectoralis major of normal rats kept on a diet of bread and lean meat show fat intermediate in amount to that represented in figures 1 and 2 . In several rats the superficial fibers of the pectoralis major contained less fat than those somewhat removed from the surface. The fibers illustrated in the figures were not superficially placed. After rats have been fed on fat meat for a few days, the quantity of fat in the muscle fibers appears to have been increased to the maximum. Further feeding increases the amount of connective tissue fat but seems to have no effect upon the fat in the muscle fibers. As already mentioned, dark muscle fibers are more clearly marked in well nourished animals than in emaciated animals of the same species.

The fat droplets of muscle fibers are clearly to be regarded as reserve foodstuff. The work of Bell in this respect is so convincing as scarcely to require confirmation. I have not made observations on the effect of starch, sugar or protein diets, as has Bell.

\section{SUMMARY AND CONCLUSIONS}

The interstitial granules of striated muscle may be classed as true interstitial granules and fat droplets as was done by Kölliker. Both the granules and fat droplets are factors in bringing about the dark or cloudy appearance of muscle fibers.

The two types of fibers, dark and light, the occurrence of which is well known in adult vertcbrates, are also present in the muscles of the fetus.

The terms "red and white muscle" refer to macroscopical color differences only. Applied to the microscopic appearance of muscle fibers these terms become a misnomer if used as synonymous with "dark and light muscle fibers."

The interstitial granules and fat droplets of muscle are somewhat uniformly arranged in longitudinal and in transverse rows between the muscle columns. Small granules and fat droplets form transverse rows in segment $J$ on either side of the membrane of Krause while those of larger size are in segment $Q$. The 
arrangement of the granules and fat droplets within muscle fibers is not dependent upon any connection with a fibrous net-work but is determined solely by the position of the membrane of Krause, the size of the granules, and the pressure of the muscle columns.

The true interstitial granules are of a soft, plastic substance and have no limiting membrane.

The exact chemical nature of the true interstitial granule is unknown. They are certainly not composed wholly of fat, though they contain an alcohol-soluble clement. As was suggested by Regaud, they may be an albumino-lipoid.

Many fat droplets in muscle fibers are not preserved by formalin fixation. After a variable length of time in formalin fixatives the droplets may disappear. Fresh tissues must be used if all the droplets are to be demonstrated. This confirms a conclusion drawn by Bell.

Fat droplets in muscle fibers are frequently stained but faintly or left colorless by the commonly used solutions of Scharlach $R$ and Sudan III in 70 per cent alcohol. Alkaline-alcoholic solutions of Scharlach $R$ applied to fresh tissue stain all the fat droplets of muscle fibers. By this method preparations may sometimes be shown to be loaded with fat droplets when none are stained by the simple alcoholic solutions.

Nile blue sulphate and Nile blue chlorhydrate color all the fat droplets of muscle fibers when fresh tissue is used and stained sections are placed in alkaline water or mounted in an alkaline medium. The droplets are usually colored red, but under certain conditions they stain blue. With favorable material, pectoral muscles of pigeon and bat, after a short formalin fixation, both true interstitial granules and fat droplets may be stained in the same preparation, the former blue, the latter red.

Many fat droplets of muscle fibers are not blackened by osmium tetroxide.

For the most part the fat droplets of muscle fibers are neutral fat, glycerin esters of fatty acids. No convincing evidence has yet been presented to show that the fat droplets contain any substance other than neutral fat. They may not be pure neutral fat but it is improbable that they contain any considerable amount of albumin or other non-fatty substance. 
Both true interstitial granules and fat droplets are of wide distribution in striated muscle, occurring under normal physiological conditions both in insect muscle, and also in the skeletal and cardiac muscle of vertebrates.

The physiological significance of the true interstitial granules is uncertain.

The quantity of fat in muscle fibers is increased when the animal (rat) is fed on fat meat and decreased during inanition. The fat droplets of muscle fibers are reserved food material. This conclusion was reached by Bell.

This study was conducted under the direction of Prof. Irving Hardesty and I am under obligation to him for many helpful suggestions. I am also indebted to Prof. Gustav Mann who has given me valuable assistance.

\section{LITIRATURE CITED}

Albrecht, F. 1902 Neue Beiträge zur Pathologie der Zelle, Deutsche path. Gesellschaft, Bd. 5.

1903a U̇ber trübe Schwellung und Fettdegeneration.

Deutsche path. Gesellschaft, Bd. 6 .

1903b Uther die Bedeutung myelinogener Substanzen im Zelleben. Deutsche path. Gesellschaft, Bd. 6 .

Altmann, R. 1894 Die Elementarorganismen.

ARNoLD, J. 1900 Utber vitale Granulafärbung in den Knorpelzellen, Muskelfasern und Ganglienzellen. Arch. f. mikr. Anat., Bd: 55.

1909a Zur Morphologie des Muskelglyeogens und Zur Struktur der quergestreiften Muskelfaser. Arch. f. mikr. Anat., Bd. 73.

1909b Zur Morphologie des Glykogens des Herzmuskels nebst Bemerkungen über dessen Struktur. Arch. f. mikr. Anat., Bd. 73.

AschоғF, L. 1909 Zur Morphologie der lipoiden Substanzen. Zieglers Beiträge, Bd. 47.

BELL, E. T. 1909 On the occurrence of fat in the epithelium, cartilage, and muscle fibers of the ox. Am. Jour. Anat., vol. 9.

1910 The staining of fats in epithelium and muscle fibers. Anat. Rec., vol. 4.

1911 'The interstitial granules of striated muscle and their relation to nutrition. Internet. Monatsehrift f. Anat. u. Phys., Bd. 28.

BendA, C. 1900 Eine makro-und mikrochemische Reaktion der Fettgewebsnekrose. Virchows Arch., Bd. 161.

Eisenberg, P. 1910 Über Fiettfärbung. Farbchemische und histologischtechnische Untersuchungen. Virchows Arch., Bd., 199.

Ewald, A. 1910 Helle und trübe Muskelfasern beim Menschen. Münch. Mediz. Wochenschrift, Jahrg. 57, No. 7. 
Fauré-Fremiet, M. E. Mater, A., et Schaefrer, G. 1910 Sur la microchimie des corps gras; application a l'étude des mitochondries, Arch. d'Anat. mikrosc., tome 12 .

Fischler, F. 1904 Über die Unterscheidung von Neutral-fetten, Fettsäuern und Seifen im Gewebe. Zentralb. f. allg. Path. u. path. Anat., Bd. 15 S. 913.

GRÜtzner, P. 1884 Zur Anatomie und Physiologie der quergestreifton Muskeln. Reeueil Zoolog. suisse, tome 1 .

Heidenhaix, M. 1901 Ủber die Struktur des menschlichen Herzmuskcls. Anat. Anz., Bd. 20.

Herxheimer, G. 1901 Utber Fettfarbstoffe. Deutsche med. Wochenschrift, S. 607 .

1904 Über Fett-Infiltration und Degeneration. Lubarsch-Ostertag: Ergebnisse der allg. Path und path. Anatomie, Bd. 8.

Holmgries, E. 1907 Über die Sarcoplasmakörner quergestreiften Muskelfasern. Anat. Anz., Bd. 31.

1907 Uber die Trophospongion der quergestreiften Muskelfasern. Arch. f. milkr. Anat., Bd. 71 .

1910 Untersuchungen über die morphologisch nachweisbaren stofflichen Umsetzungen der quergestreiften Muskelfasern. Arch. f. mikr. Anat., Bd. 75.

KEINATH, K. T. 1904 Über den mikroskopisehen Nachweis von Fett in normalen Muskeln. Inaug.-Dissert., Freiburg.

KEMP, G. T. AND HALI, L. B. 1907 The formation of fat in animals fattencd for slaughter. Amer. Jour. Physiol, vol. 18 (Proceedings of the physiol. society).

Kingsbury, B. F. 1912 Cytoplasmie fixation. Anat. Rec,, vol. 6.

Kıotz, O. 1906 Studies upon calcarious degeneration. Jour. Exp. Med., vol. 8. 1909 On the large white or soapy kidncy. Jour. Med. Research, vol. 20.

KNoche, V. 1909 Utber die Struktur der sogenannten 'interstitiellen Körner' (Kölliker) der Flugelmuskelfaser der Tnsokten, Anat. Anz., Bd. 34.

KNoll, P. 1880-81 Utber Myokarditis und die übrigen Folgen der Vagusselstion bei Tauben. Zeitschr. f. Heilkunde., Bd. 1.

1889 Uber helle und trübe, wcisse und rothe queregestreifte Muskulatur. Sitz. d. Kais. Akad. d. Wiss. Wien, Bd. 98.

1891 Über protoplasmaarme und protoplasmareiche Muskulatur, Denkschr. d. Kais. Akad. d. Wiss. Wien, Bd. 58.

KNoll, P., Und Haugr, A. 1892 Utber das Verhalten der protoplasmaarmen und protoplasmareichen, quergestreiften Muskelfasern unter pathologischen Verhaltnissen. Sitzungsber. der kaiserl. Akad. der Wissensch., mathem.-naturw. Cl., 101. 3. Abt.

KöLlIK®R, A. 1857 Einigo Bemerkungen über die Fndigungen der Hautnerven und den Bau dor Muskeln. Zeitschr. f. wiss. Zool. Bd. 8; (cited from Retzius and Bell).

1888a Zur Kenntnis der quergestreiften Muskelfasern. Zeitschr. f, wiss. Zool., Bd. 47 ; (cited from Retzius and Bell).

1888 b Ueber den Bau der quergestreiften Muskelfasern, Sitz. d.Würzb. phys.-med. Gesellschaft. 
KöLlik er, A. 1889 Gewebelehre. 6. Aufl. 1.

Kradse, W. 1864 Die Anatomie des Kaninchens. Leipsig; (cited from Schaeffer). 1873 Die contraction der Muskclfaser. Pflügers Archiv. f. Physiologie, Bd. 7 .

Krause, Rud. 1911 Kursus der Normalen Histologie. Berlin and Wien.

Lelivire, Atg., et Retterer, Ed. 1909 Des differences de structure des muscle rouges et blanes du lapin. Comptes Rendus Soc. Biologie, tome 66 , f. 1075 .

MCCraE, J., AND KLOTz, O. 1910 The distribution of fat in the liver. Jour. exp. med., vol. 12 ., no. 6 .

Prenant, A. 1911 Problemes cytologiques generaux souleves par l'etude des cellules musculaires. III et IV, Jour. Anat. et Physiol. tome 47, no. 6.

REGAUD, CL. 1909 Sur les mitochondries des fibres musculaires du coeur.C.R. Acad. Sciences, tome 149.

Regaud, C., ex Favre, M. 1909 Granulations interstitielles et mitochondries des fibres musculaires strićes. C. R. Acad. Sciences, tome 148.

Retzius, G., 1890 Muskelfibrille und Sarkoplasma. Biologisehe Cntersuchungen. Stockholm. N. F. I.

Ricker, G. UNd Etienkeck, J. 1899 Beträge zur Kenntnis der Veränderungen des Muskels nach der Durchschneidung seincs Nerven. Virchows Archiv, Bd. 158.

ScHAFFER, J. 1893 Beiträge zur Histologie und Fistogeneso der quergestreiften Muskelfasern des Menschen und einiger Wirbeltiere. Sitz.d. $\Lambda$ kad. d. Wiss. Wien, Bd. 102.

Smith, J. Lorrais 1906 The staining of fat with basie anilin dyes. Jour. Path. and Bacter., vol. 11, p. 415.

1907 On the simultaneous staining of neutral fat and fatity acid by oxazine dyes. Jour. Path. and Bacter., vol. 12, p. 1.

1910 The staining of fat by Nile blue sulphate. Jour. Path. and Bacter., vol. 75, p. 53 .

Smith, J. Lorrain, MaIR, W. and Thorpe, J.F. 1908 An investigation of the principles underlying Weigert's method of staining medullated nerve. Jour. Path. and Bacter., vol. 13. p. 14.

Smith, J. LonRain, AND MaIr, W. 1910 Further observations on the bichromate hacmatoxylin method of staining lipoids. Jour. Path. and Bacter., vol. 15 , p. 179 .

1911 Fats and lipoids in relation to methods of staining. Skandin. Arch. f. Physiol., Bd. 25.

Statkewitsch, P. 1894 Über Veränderungen des Muskel- und Dräsengewebes sowie der Herzganglien beim Hungern. Archiv. f. experim. Path. u. Pharmakol., Bd. 33.

Thulin, I. 1909 Morphologische Studien über die Frage nach Ernährung der Muskelfasern. Skandin. Arch. f. Physiol., Bd. 22.

van Gehuchten, A. 1859 Les noyaux des cellules musculaires striees de la grenouille adulte. Anat. Anzeiger, Bd. 4.

Walbatu, O. 1899 Cntersuchungen über die quergestrcifte Muskulatur mit besonderer Berïcksichtigung der Fettinfiltration. Virchows Archiv, Bd. 158. 